\title{
On Situating the Stance of Practice in SLA
}

\author{
Parviz Maftoon \\ College of Foreign Languages and Literature, Science and Research Branch, IAU, Tehran, Iran \\ pmaftoon@srbiau.ac.ir \\ Nima Shakouri (corresponding author) \\ Roudbar Branch, Islamic Azad University, Rasht, Iran \\ shakouri.ni@gmail.com \\ Ogholgol Nazari \\ Sama Technical and Vocational Training College, IAU, Gorgan Branch, Gorgan, Iran \\ nazari97@yahoo.com
}

Received: 20-11- 2012

Accepted: 28-12- 2012

Published: 01-03- 2013

doi:10.7575/aiac.ijalel.v.2n.2p.71

URL: http://dx.doi.org/10.7575/ijalel.v.2n.2p.71

\begin{abstract}
The study of skill acquisition, as DeKeyser (1997) declares, is an important area within cognitive psychology. What is undeniable in skill acquisition is the fact that through extensive practice, the degree of attention on a task decreases and the task is performed without stopping; furthermore, the rate of error considerably decreases. The paper, in an attempt to work on situating the concept of practice in skill acquisition, goes on to hold that since each context has its own specific encoding cues, and that the skill achieved in that specific context is too specific to be transferred to other contexts, the degree of automaticity in employing the skill in that context is plausibly more than the other contexts.
\end{abstract}

Keywords: Skill specificity, Practice, Automaticity, Fluency, Interface

\section{Introduction}

Skill specificity as a new issue within the skill acquisition theory has attracted the attention of several researchers (e.g., Anderson, 1985; Dekeyser, 1997). However, research in this field is still scarce. What the linchpin of skill acquisition theory is centered on is the claim that no transfer of practice between comprehension and comprehension skills takes place (DeKeyser, 1997; Van Patten \& Cardieno, 1993). Quite on the same par, skill acquisition theory "accounts for how people progress in learning a variety of skills, from initial learning to advanced proficiency" (DeKeyser, 2007a). Henceforth, according to DeKeyser:

the basic claim of skill acquisition theory is that the learning of a wide variety of skills shows a remarkable similarity in development from initial representation of knowledge through initial changes in behavior to eventual fluent, largely effortless, and highly skilled behavior and this set of phenomena can be accounted for by a set of basic principles common to the acquisition of all skills. (p. 97)

The paper, in revisiting the nature of specificity of practice, asserts that those who develop the knowledge specifically enjoy some form of privileged status in memory because information can be retrieved more easily and faster. In this regard, Schunk (2012) claims, "retrieval depends on the manner of encoding" (p. 201). That is, the manner in which knowledge is encoded determines which retrieval cues will effectively activate the knowledge. Imagine students were given a partial list of U.S. states to read; others read no list. Subsequently all students recalled as many states as they could. Students who received the list recalled more of the states on the list and fewer states not on it (Brown, 1968, cited in Schunk, 2012, p. 201).

\section{On the nature of skill specificity}

Skill specificity refers to the issue that performance improves most in the type of task that has been practiced (Dekeyser, 1997), i.e., production practice leads to increased production skills, and comprehension practice to increased comprehension skills. Some influence between the two types of tasks may occur as a result of the more flexible declarative knowledge, but not proceduralized knowledge (de Jong, 2005). Several scholars (e.g., Bates \& MacWhinney, 1989) claim that comprehension and production make use of the same system of representation view, but the real-time exigencies of processing may be quite different. Rather on the same par, Truscott and Sharwood-Smiths (2004) go on to hold that production involves the same items and mechanisms as comprehension except in reverse. It implies that acquisition takes place when processing adds new items, alters old items, or raises resting levels of activation. As de Jong (2005) reports: 
If learners receptively process a sentence with a case-marked noun, the syntactic processor will connect the noun to one of the case items in syntactic structure (e.g., nominative or accusative). If no suitable case item exists, a new item is created. Although the new item was specifically created for the purpose of building the current representation, it does not disappear. Its resting level of activation is low initially but rises quickly through continued use. The new representation is now available for comprehension as well as production. ( $p$. 19)

Having no answer to this question whether the practice of components of a task is better or worse than the whole components, DeKeyser (2007b) brings us to the related question of specificity of practice effects in skill acquisition. Along the same line, skill specificity, as to Byun (2007), is “the output practice as a valuable factor affecting a learner's linguistic developing system" (p. 16).

The importance of production practice in SLA has been emphasized by many researchers (DeKeyser, 1997; Swain, 1985). In this regard, DeKeyser and Sokalski (2001, as cited in Byun, 2007) argue that "a morphologically complex structure may be easier to notice but harder to produce correctly than a simpler structure; a simpler structure may be inconspicuous and therefore harder to notice, but easier to produce by virtue of its simplicity" (p. 24). In fact, skill specificity argues that performance improves most in the type of task that has been practiced. Thus, production practice leads to an increase in production skills, and skill-specificity may not apply to the acquisition of comprehension ability (Byun, 2007).

This specificity of the practice effect can also be explained via the distinction made by Anderson (1985) between declarative and procedural knowledge. According to Anderson declarative knowledge is knowledge that can be declared, usually in words. Procedural knowledge, in contrast, is 'knowing how' to perform a task such as washing an engine. To Anderson, declarative and procedural knowledge are different kinds of knowledge as they are stored differently. As Anderson (1985) claims practice enables declarative knowledge to become preoceduralized knowledge. Along the same line, DeKeyser (2007a) goes on to hold that in most forms of skill acquisition, people are first presented with declarative information, and then through initial practice, this declarative information is converted into behavioral routines. As procedural knowledge possesses specific rules that can be used very fast and with low rate of errors, such knowledge lacks generalizability (Dekeyser, 2007b). That is, research, in line with skill specificity, shows that each context favors or requires specific types of practice activities; as a result, different learning contexts promote significant skill-specific improvement (DeKeyser, 1997).

What we need here to better appreciate the concept of the newly developed knowledge (i.e., procedural knowledge) and further our discussion is to know that knowledge is more than the end product of previous learning; it also guides new learning (Woolfolk, Winne, \& Perry, 2002). In the same line, Alexander (1996) asserts what we know is a scaffold that supports the construction of all future learning. Henceforth, initially, a learner acquires a bit of knowledge about a skill without an ability to use it. In most cases, such knowledge is transmitted from one expert to a novice, mostly in verbal forms. Then, the 'knowledge that' is converted into the 'knowledge how' - declarative knowledge to procedural knowledge. That is, at this stage, declarative knowledge is to be demonstrated. Anderson (1985) goes on to hold that for declarative knowledge to become preoceduralized knowledge, practice is needed. To him, all knowledge starts out in declarative; however, such declarative-to-procedural concomitance was not later generalized by Anderson, especially with respect to second language learning. Anderson, inspired by Fitts and Posner (1967), formulated three stages to explain how skill acquisition takes place, or, better to say, how declarative knowledge is turned into procedural knowledge: (1) the cognitive stage (i.e., a description of procedure is learned, e.g., singular $-s$ must be added to the verb preceded by a singular subject), (2) the associative stage (i.e., a method for performing the skill is worked out), and (3) the autonomous stage (i.e., the skill becomes more and more rapid and automatic).

DeKeyser (2007b) asserts proceduralized knowledge is a big advantage over declarative knowledge, as it no longer requires the individual to retrieve bits and pieces of information from memory to assemble them into a program for a specific behavior. DeKeyser, pointing out that a relatively small amount of practice may lead to proceduralization, puts forth that the advantage of procedural knowledge over declarative knowledge rests in the fact that it is available as "a ready-made chunk to be called up in its entirety each time the conditions for that behavior are met" (p. 98). However, the acquisition of procedural knowledge does not guarantee that the target skill will be performed proficiently (Mystkowska-Wiertelak \& Pawlak, 2012). Furthermore, for the proceduralized knowledge to be displayed efficiently, it needs to be automatized; that is, the behavior needs to become automatic. For this to happen, DeKeyser (2007a) holds "a large amount of practice is needed to decrease the time required to execute the task (reaction time), the percentage of errors (error rate), and the amount of attention required" (p. 98). DeKeyser goes on to assert that the "process of porceduralization and automatization cannot get started if the right conditions for proceduralization are not present" (p. 100). Elsewhere, DeKeyser (1997) has contended when forms are practiced repeatedly in a meaningful context, proceduralization and automatization can take place. Henceforth, DeKeyser recommends explicit instruction followed by meaningful activities be designed to promote proceduralization. These activities, according to (Hattem, 2011), should not be rushed and should allow the learner ample time and opportunities to access their declarative knowledge before proceeding to more free-based exercises and activities.

\section{Practice and the power law of learning}

Carlson (1997, cited in DeKeyser, 2007b) defines practice simply as a "repeated performance of the same (or closely similar) routines" (p. 2). However, the notion of practice is controversial. It may be equated with mechanical drills. To 
stop misunderstanding and offering such misjudgment regarding the notion of practice, DeKeyser (2007b) presents a focused definition of practice as "specific activities in the second language, engaged in systematically, deliberately, with the goal of developing knowledge of and skills in the second language" (p. 1). Therefore, practice should be meaningful and should employ intentional focus on form. Along the same vein, DeKeyser argues that one of the central questions regarding practice in SLA is whether practice affects SLA, and if so, whether the effect is skill-specific or not.

In line with the power law of learning, it is frequently claimed that learning performance improves with practice according to the so-called power law of learning. In its simplest form, a power function is a function of the shapes $P=t^{\mu}$, where $\mu$ is the learning rate parameter, and $t$ is number of learning episodes or time. $P$ may refer to how accurate or how fast we carry out a learned activity (Murre \& Chessa, 2011). Thus, what is implied is that our learning does not occur at a constant rate. Research by Logan (1992) suggests that the theory of automaticity can be used to explain why the power law is deemed an accurate portrayal of reaction time learning curves. In effect, a skill becomes automatic when there is no effort on the part of learners to retrieve information. However, automatization is not easy to be defined. DeKeyser (2007b) reports the reason as the term is used at three levels of generality:

In the broadest sense, it refers to the whole process of knowledge change from initial presentation of the rule in declarative format to the final stage of fully spontaneous, effortless, fast, and errorless use of that rule, often without being aware of it anymore. In a narrower sense, it refers to the slow process of reducing error rate, reaction time, and interference with/from other tasks that takes place after proceduralization. In the most specific sense, it designates a merely quantitative change in the subcomponents of procedural knowledge to the exclusion of any qualitative change or restructuring (i.e., excluding changes in which small subcomponents make up procedural knowledge at a given stage of skill development or how they work together. (p. 4)

Generally speaking, the power law of learning is the central concept of skill acquisition that relates to the last two levels of generality mentioned above (DeKeyser, 2007b). DeKeyser (2007a) holds that "both reaction time and error rate decrease as a consequence of practice" (p. 99). Accordingly, he declares this decrease follows a very specific mathematical function referred to as the power law. As Dekeyser asserts practice in each skill-production/comprehension skills--reinforces the declarative knowledge that is applicable to both. However, the procedural knowledge is too specific to be transferred from one skill to another. One can, therefore, arrive at the conclusion that practice effect is highly skill-specific.

\section{Interface discussion}

The relation between implicit and explicit knowledge, more specifically, whether one can change into the other or whether they interact, has been much debated (Anderson, 1985; DeKeyser, 1997; Krashen, 1985). In a nutshell, there are three possible interfaces. The proponents of interface position (Anderson, 19985; DeKeyser, 1997) put forth that explicit knowledge can turn into implicit knowledge after a sufficient amount of practice. In a non-interface model, according to Hulstijn (2001), what is learned explicitly cannot turn into implicit knowledge. A notable figure who is in favor of non-interface position is Krashen (1985) who was first to make a distinction between learning and acquisition. To him, learning is a conscious process that results in knowing about language, while acquisition is a subconscious process that results in tacit linguistic knowledge. To Krashen, learning and acquisition cannot change into each other.

Schwartz (1993), in line with Krashen (1985), maintains that the theory of modular mind is considered as a reinforcement of Krashen's learning and acquisition hypothesis. That is, Fodor's (1983) concept of modular systems that are unaffected by conscious knowledge supports Krashen's non-interface position. In other words, conscious learning and subconscious learning are unrelated, and that both the grammar of language and the uses of language are acquired unconsciously. Schwartz (1986), attempting to reconcile Fodor's (1983) Language Module with Chomsky's (1957) Language Faculty, declares that there is an innately given module specific for the domain of the language. This module, as Fodor (1983) maintains, is informationally encapsulated. It can only accept as input those representations that are compatible with it. Henceforth, de Jong (2005) declares as "explicit knowledge is not of the correct type, it cannot feed into the module and has no effect on the language system and processes" (p. 10).

The third stance regarding interface discussion is a weak interface position which claims that explicit knowledge cannot turn into implicit knowledge but can influence the acquisition of implicit knowledge (VanPatten \& Cadierno, 1993). As de Jong (2005) continues "explicit knowledge may make specific features of the input more available for learning, for instance, by focusing attention or changing the way input is processed, or by making learners notice the gap between the input and their own production" (p. 10).

\section{Automaticity}

There is a commonly held belief that automaticity is the ability to do things without occupying the mind with the lowlevel details. Posner and Boies (1978) and Newell (1990), for instance, both share in this view that automaticity is fast and ballistic. It is natural to think that once a mechanism has become automatic it will operate faster than it did earlier. However, Mirahmadi, Jalilzadeh, and Nosratzadeh (2011) claim that while automatic processing may entail fast processing, it does not follow that all fast processing is necessarily automatic. Along the same vein, Mirahmadi et al go on to hold:

This is because "fast" is nearly always understood in a relative rather than absolute sense. It is, for example, logically possible for a given individual to exhibit faster non-automatic processing on 
one occasion than on another, or for two individuals to differ in the speed of executing nonautomatic aspects of task performance. Hence, merely observing that performance was fast does not necessarily indicate it was automatic.

In a more comprehensive definition, Kahneman (1973) defines automaticity as the absence of attentional control in the execution of a cognitive activity. Along the same line, Mitchell and Myles (2004) hold that automatic processes do not need attentional control. In fact, automaticity is the ability to perform a complex task quickly, with few attentional resources (LaBerge \& Samuels, 1974). LaBerge and Samuels also assert that automaticity develops as the result of extended practice, wherein a complex task that once was slow and required a great deal of attention gradually becomes automatic. Seen from this stance, we can claim that if one's skill in a particular domain increases, his/her effort and attention to perform that skill decreases. Put similarly, while automatic processing may entail fast processing, it does not follow that all fast processing is necessarily automatic. The term automaticity covers a wide range of phenomena that often vary from one definition to another (Cohen, Servan-Schreiber \& McClelland, 1992). Nevertheless, Cohen et al. believe that there are a core set of phenomena that seem to occur in most discussions of automaticity:

1. an increase in speed of performance with practice following a power law,

2. diminishing requirements from attention with practice,

3. a commitment release from attentional control--or involuntariness (i.e., the involuntariness of automatic processes)

4. immunity from interference with competing processes, and

5. the requirement that practice be "consistently mapped" for these phenomena to develop. (pp. 241-242)

\section{Fluency or automaticity}

According to Hudson, Pullen, Lane, and Torgesen, (2009), the terms automaticity and fluency are often used interchangeably. It is not in the realm of paper to make automaticity and fluency distinct, but what makes our mind obsessed is to find an answer to the following questions: How can you tell whether someone is fluent or automatic in a skill? What is the measurable indicator of fluency and automaticity? Although such questions are at the core of every learner's performance evaluation, there is a commonsensical understanding that being fluent means achieving a useful pace of performance. However, fluency goes beyond rapid performance.

Fluency, in fact, contributes directly to three types of critical learning outcomes: (1) the ability to recall knowledge long after learning program (retention and maintenance), (2) the ability to maintain performance levels and attention to task for extended period while raising distraction, and (3) the ability to perform and apply what is learned to perform more complex skills creatively (Binder, Haughton, \& Bateman, 2002). Binder et al. further claim what makes a student who easily completes his/her task with the one who completes it with difficulty is a lack of fluency. The students who are fluent free up their attention for higher order applications. In other words, the students who struggle to recall a string of words will have less attention for composing what they are going to produce. In sum, word identification entails anticipation of what is going to come next. Henceforth, the ability to anticipate reduces the time required to execute the task and the amount of attention.

\section{Conclusion}

As DeKeyser (2007a; 2007b) insists, the transfer between production/comprehension skills is determined by the fact that practice in each skill reinforces, to some degree, the declarative knowledge that is applicable to both. The procedural knowledge, however, is too specific to be transferred from one skill to another; therefore, practice effect is highly skill-specific. For instance, a mechanic having the procedural knowledge of how to work on a car does not necessarily have the procedural knowledge of working on an airplane.

In this regard, this is a commonly-held belief that for a skill to be employed practice is inevitable. Regarding the importance of practice, Westwood (2004) asserts that "one of the main benefits resulting from practice is the development of automaticity" (p. 15). Westwood continues when recall of information becomes automatic, less effort is required on the part of learners and it becomes much easier to do two things simultaneously. What makes automatized knowledge distinct from implicit knowledge is that while implicit knowledge is always defined with reference to lack of consciousness, absence of awareness is not a requirement for automaticity. Hence, one can have knowledge that is implicit but not automatic because error rate is too high and speed is too low (Dekeyser, 2007b). However, as Ellis and Bogart (2007) state many aspects of a second language are unlearnable or are acquired very slowly from implicit processes alone. Grammatical functors, for instance, abound in the input, but, as the result of their low salience, they are simply not implicitly learned by many naturalistic learners whose attentional focus is on meaning and communication (Ellis, 2006).

In sum, as Mystkowska-Wiertelak and Pawlak (2012) put, "an obvious advantage of Skill-Learning Theory is that it fits with other aspects of cognitive science" (p. 49). That is, the processes of SLA can be explained in the same way as those responsible for mastering other skills, such as riding a bike or learning to read. 


\section{References}

Alexander, P. A. (1996). The past, present, and future of knowledge research: A reexamination of the role of knowledge in learning and instruction. Educational psychologists, 31, 89-92. Doi:101080/2F00 461520.1996.10524941

Anderson, J. R. (1985). Cognitive psychology and its implications. New York: Freeman.

Bates, E., \& MacWhinney, B. (1989). Functionalism and the competition model. In B. MacWhinney \& E. Bates (Eds.), The crosslinguistic study of sentence processing (pp. 3-73). Cambridge: Cambridge University Press.

Binder, C., Haughton, E., \& Bateman, B. (2002). Fluency: Achieving true mastery in the learning process. Retrieved in 2012, from http://www.fluency.org/Binder_Haughton_Bateman.pdf

Byun, J. S. (2007). Processing instruction and skill-specificity: In which direction should they go? The Linguistic Association of Korea Journal, 15(1), 15-35.

Chomsky, N. (1957). Syntactic structures. Paris: Mouton.

Cohen, J. D., Servan-Schreiber, D., \& McClelland, J. L. (1992). A parallel distributed processing approach to automaticity. American Journal of Psychology, 105(20), 239-269.

de Jong, C. A. M. (2005). Learning second language learning by listening (Unpublished doctoral thesis). Amsterdam University, Amsterdam.

DeKeyser, R. M. (1997). Beyond explicit rule learning: Automatizing second language morphosyntax. Studies in Second Language Acquisition, 19, 195-222.

DeKeyser, R. M. (2001). Automaticity and automatization. In P. Robinson (Ed.), Cognition and second language instruction (pp. 125-51). Cambridge: Cambridge University Press.

DeKeyser, R. M. (2007a). Skill acquisition theory. In B. VanPatten \& J. Williams (Eds.), Theories in second language acquisition (pp. 97-113). London: Lawrence Erlbaum Associates

DeKeyser, R. M. (2007b). Introduction: Situating the concept of practice. In R. M. DeKeyser (Ed.), Practice in a second language: Perspectives from applied linguistics and cognitive psychology (pp. 1-18). Cambridge: Cambridge University Press.

Ellis, N. C. (2006). Selective attention and transfer phenomena in SLA: Contingency, cue competition, salience, interference, overshadowing, blocking, and perceptual learning. Applied Linguistics, 27, 1-31.

Ellis, N. C., \& Bogart, S. H. (2007). Speech and language technology in education: The perspective from SLA research and practice. Speech and Language Technology in Education. Retrieved in 2012, from http://www.iscaspeech.org/archive

Fitts, P. M., \& Posner, M. I. (1967). Learning and skilled performance in human performance. Belmont: Brock-Cole. Fodor, J. A. (1983). The modularity of mind: An essay on faculty psychology. Cambridge: MIT Press.

Hattem, D. (2011). The practice of microblogging. Journal of Second Language Teaching and Research, 1 (2), 38-70.

Hudson, R. F., Pullen, P. C., Lane, H. B., \& Torgesen, J. K. (2009). The complex nature of reading fluency: A multidimensional view. Reading \& Writing Quarterly, 25, 4-32. Doi: 10.1080/10573560802491208

Hulstijn, J. (2001). Intentional and incidental second language vocabulary learning: A reappraisal of elaboration, rehearsal and automaticity. In P. Robinson (Ed.), Cognition and second language instruction (pp. 258-86). Cambridge: Cambridge University Press.

Kahneman, D. (1973). Attention and effort. New York: Prentice-Hall.

Krashen, S. D. (1985). Second language acquisition and second language learning. Oxford: Pergamon.

LaBerge, D., \& Samuels, S. J. (1974). Toward a theory of automatic information processing in reading. Cognitive Psychologist, 6, 293-323.

Logan, G. (1992). Shapes of reaction-time distributions and shapes of learning curves: A test of the instance theory of automaticity. Journal of Experimental Psychology: Learning, Memory, and Cognition, 18 (5), 883-914.

Mirahmadi, H., Jalilzadeh, K., \& Nosratzadeh, H. (2011). Skill acquisition Theory in second language acquisition: A focus on productive skills. International Comference on Languages, Literature and Linguistics (pp. 197-201). Singapore: IACSIT Press.

Mitchell, R., \& Myles, F. (2004). Second language theories. London: Hodder Arnold.

Murre, J. M. J., \& Chessa, A. G. (2011). Power laws from individual differences in learning and forgetting: Mathematical analysis. Psychology Bulletin \& Review, 18 (3), 592-597. Doi: 10.3758/s13423-011-0076-y

Mystkowska-Wierelak, A., \& Pawlak, M. (2012). Production-oriented and comprehension-based grammar teaching in the foreign language classroom. London: Springer.

Newell, A. ( 1990). Unified theories of cognition. Cambridge, M.A.: Harvard University Press.

Posner, M.I. , \& Boies, S. J. ( 1978). Components of attention. Psychological reviews, 78, 391-408.

Schunk, D. H. (2012). Learning theories: An educational perspective. Boston: Pearson Education Inc. 
Schwartz, B.D. (1986). The epistemological status of second language acquisition. Second Language Research, 2, 12059.

Schwartz, B. D. (1993). On explicit and negative data effecting and affecting competence and linguistic behavior. Studies in Second Language Acquisition, 15 (2), 147-163.

Swain, M. (1985). Communicative competence: Some roles of comprehensible input and comprehensible output in its development. In S. M. Gass \& C. Madden (Eds.), Input in second language acquisition (pp. 235-253). Rowley, MA: Newbury House.

Truscott, J., \& Sharwood-Smith, M. (2004). Acquisition by processing: A modular perspective on language development.Bilingualism: Language and Cognition, 7 (1), 1-20.

VanPatten, B., \& Cadierno, T. (1993). Explicit instruction and input processing. Studies in Second Language Acquisition, 15, 225-243.

Westwood, P. (2004). Learning and learning difficulties: A handbook for teachers. Hong Kong: ACER Press.

Woolfolk, A. E., Winne, P. H., \& Perry, N. E., (2002). Educational psychology. Toronto: Pearson Education. 